\title{
Health-related quality of life in adolescents with screening-detected celiac disease, before and one year after diagnosis and initiation of gluten-free diet, a prospective nested case-referent study
}

\author{
Katrina Nordyke*, Fredrik Norström, Lars Lindholm, Hans Stenlund, Anna Rosén and Anneli Ivarsson
}

\begin{abstract}
Background: Celiac disease (CD) is a chronic disorder in genetically predisposed individuals in which a small intestinal immune-mediated enteropathy is precipitated by dietary gluten. It can be difficult to diagnose because signs and symptoms may be absent, subtle, or not recognized as CD related and therefore not prompt testing within routine clinical practice. Thus, most people with CD are undiagnosed and a public health intervention, which involves screening the general population, is an option to find those with unrecognized CD. However, how these screening-detected individuals experience the diagnosis and treatment (gluten-free diet) is not fully understood. The aim of this study is to investigate the health-related quality of life (HRQoL) of adolescents with screeningdetected $C D$ before and one year after diagnosis and treatment.
\end{abstract}

Methods: A prospective nested case-referent study was done involving Swedish adolescents who had participated in a CD screening study when they were in the sixth grade and about 12 years old. Screening-detected adolescents $(n=103)$ and referents without CD who participated in the same screening $(n=483)$ answered questionnaires at the time of the screening and approximately one year after the screening-detected adolescents had received their diagnosis that included the EQ-5D instrument used to measure health status and report HRQoL.

Results: The HRQoL for the adolescents with screening-detected CD is similar to the referents, both before and one year after diagnosis and initiation of the gluten-free diet, except in the dimension of pain at follow-up. In the pain dimension at follow-up, fewer cases reported problems than referents (12.6\% and 21.9\% respectively, Adjusted OR $0.50,95 \% \mathrm{Cl} 0.27-0.94)$. However, a sex stratified analysis revealed that the significant difference was for boys at follow-up, where fewer screening-detected boys reported problems (4.3\%) compared to referent boys (18.8\%) (Adjusted OR 0.17, 95\% Cl 0.04-0.73).

Conclusions: The findings of this study suggest that adolescents with unrecognized CD experience similar HRQoL as their peers without $C D$, both before and one year after diagnosis and initiation of gluten-free diet, except for boys in the dimension of pain at follow-up.

Keywords: Adolescents, Celiac disease, EQ-5D, Health-related quality of life, Screening, Screening-detected celiac disease

\footnotetext{
* Correspondence: katrina.nordyke@epiph.umu.se

Department of Public Health and Clinical Medicine, Epidemiology and Global Health, Umeå University, Umeå, Sweden
} 


\section{Background}

Celiac disease (CD) is a chronic disorder in genetically predisposed individuals in which a small intestinal immune-mediated enteropathy is precipitated by dietary gluten [1]. The prevalence has generally been suggested to be around $1 \%$ [2-4], however more recently it has been shown that the prevalence has risen $[3,5,6]$ and most of the people with $\mathrm{CD}$ are actually undiagnosed [7-10]. CD can be difficult to diagnose because the signs and symptoms may be absent, subtle, or not recognized as $C D$ related and therefore not prompt testing within routine clinical practice [11]. The best strategy for finding those with unrecognized CD is still debated, but options include: active case finding through routine clinical practice with a broader consideration for variety in presentation, testing groups at high risk (e.g., first degree relatives of those with $C D$ or those with other autoimmune disorders), or a public health intervention that would involve screening the general population $[3,7,10,12,13]$.

Recently, Aggarwal et al. presented a review of literature that addresses how screening, diagnosing, and treating (gluten-free diet) asymptomatic individuals affects their quality of life [3]. Their overview illustrates that there is a lack of consensus on whether or not the gluten-free diet (GFD) improves the quality of life in "asymptomatic screening-detected" individuals [3]. Research addressing the quality of life (QoL) and healthrelated quality of life (HRQoL) for people with $\mathrm{CD}$ is mostly based on those diagnosed through routine clinical practice or selected for screening because they are considered at high risk [14-28]. The HRQoL for individuals who have received their $\mathrm{CD}$ diagnosis from a screening of the general population could differ from these groups and this study focuses on adolescents diagnosed with $\mathrm{CD}$ as a result of screening study. The aim of this study is to investigate the HRQoL of adolescents with screening-detected $\mathrm{CD}$ before and one year after diagnosis and treatment.

\section{Method}

\section{Design}

A prospective nested case-referent study was done involving adolescents who had participated in a CD screening study. The cases included those with screening-detected $\mathrm{CD}$ and referents were chosen from those who tested negative for the $\mathrm{CD}$ serological markers. The cases and referents reported their $\mathrm{HRQoL}$ at the time of the screening and about one year after the cases received their diagnosis.

\section{Setting}

The CD screening study that the adolescents participated in (ETICS-Exploring the Iceberg of Celiacs in Sweden) took place in 2005-2006 [8]. It involved sixth graders from 5 regions in Sweden when they were about 12 years old. The screening took place in their schools in collaboration with school health systems and regional pediatric departments. Information was provided to parents and children, written consent was obtained from parents, and ethical approval for the study was granted by the Regional Ethical Review board in Umea, Sweden [Dnr UMU 04-156-M].

\section{Participants and materials}

In total, 10041 children were invited and 7567 (75\%) consented to participate. Blood samples were collected from 7208 (72\%) children who did not already have a $\mathrm{CD}$ diagnosis. The blood samples were analyzed for $\mathrm{CD}$ serological markers and children with suspected $C D$ were referred to their pediatric department for an intestinal biopsy to confirm the diagnosis [8]. Thereafter, a GFD was recommended and follow-up care was provided according to current clinical standards.

At the time the population for this study was selected, there were 145 children with screening-detected/biopsy verified $\mathrm{CD}$ and 62 who reported having $\mathrm{CD}$ diagnosed prior to the screening and gave a blood sample. After combining these groups with $C D(n=207), 4$ referents per child were randomly chosen $(n=828)$, with the proportion of girls and boys in the referent group to match that of the group with $C D$. From the 207 children with $\mathrm{CD}, 2$ were found to be without $\mathrm{CD}$, resulting in 61 diagnosed prior to the screening and 144 screeningdetected cases (Figure 1).

The participants filled out questionnaires that included the Swedish child-friendly pilot version of the EQ-5D instrument (EQ-5D) [29-31]. The EQ-5D is a generic tool used to measure health status and report HRQoL [32]. It is comprised of two parts, the EQ-5D descriptive system where respondents classify their health status in five dimensions: mobility, self-care, usual activities, pain/discomfort, and anxiety/depression and on level of severity (no problems, moderate problems, or severe problems). The second part of the EQ-5D is a thermometer like visual analogue scale (VAS) where respondents score their health today from worst to best imaginable $(0-100)$ [32,33].

After blood samples were collected, but before the results of the screening were known, the 12-year-olds were given the questionnaires to fill out at school. Baseline EQ-5D responses were received from 138 with screening-detected CD (96\% responding) and 797 referents (96\% responding). Approximately one year after the screening, follow-up questionnaires were mailed to the homes of those considered cases and referents for this nested-case referent study. Follow-up EQ-5D responses were received from 110 


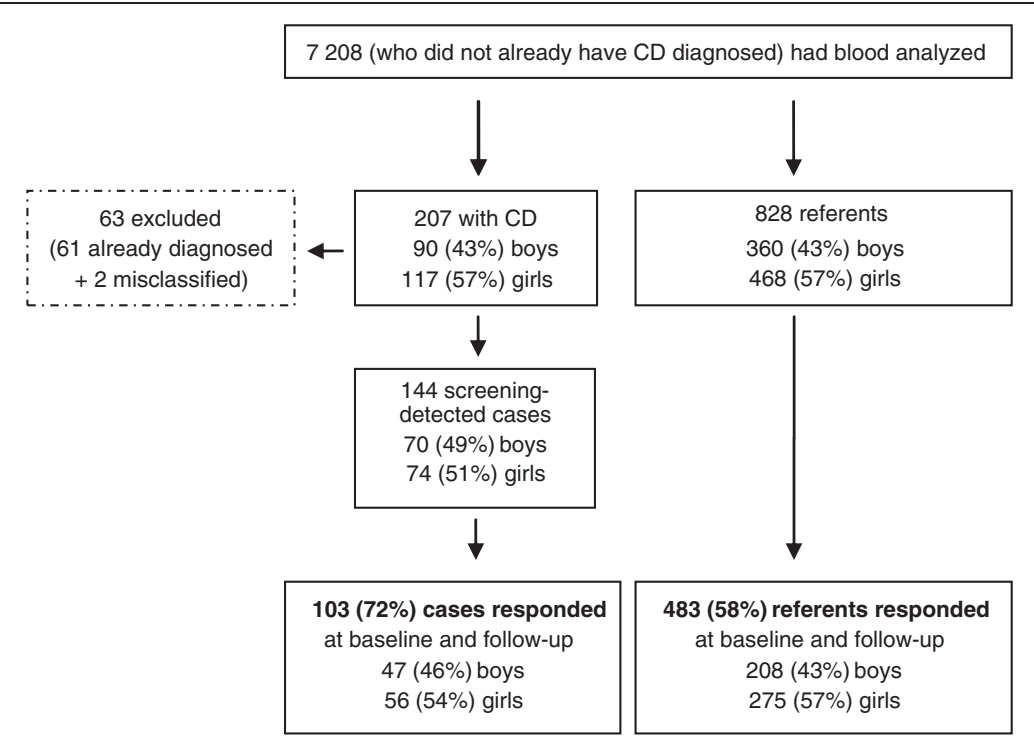

Figure 1 Participants.

with screening-detected $\mathrm{CD}$ (76\% responding) and 501 referents (61\% responding).

Responses were included for the screening-detected cases and referents when they had provided answers for all five dimensions and on the VAS at both baseline and follow-up (cases $n=103$ and referents $n=483$ ) (Figure 1). The median age of the cases at the time of the diagnostic biopsy was 13.2. Because the participants answered the questionnaires approximately one year after the cases had received the diagnosis their median age was 14.6 and we consider them adolescents at follow-up.

\section{Analysis}

Number and proportion of adolescents reporting problems were explored for each dimension. Because few adolescents reported severe problems, levels of severity were collapsed into "no problems" (from level no problems) and "problems" (from levels some problems and severe problems) [33]. The statistical software package SPSS 19 (SPSS Inc., Chicago, IL) was used and statistical significance was defined at the $5 \%$ level.

Cross tabulations were done separately for each dimension and for baseline and follow-up to illustrate the proportion reporting problems. Bivariate logistic regression was used to compare the proportion reporting problems for the cases and referents separately at baseline and follow-up, and between the cases and referents at baseline and follow-up, for each dimension. Then, in order to assess and compare crude and adjusted odds ratios (OR) and confidence intervals $(\mathrm{CI})$, multivariate logistic regression analyses were also performed for each dimension. In the logistic regression models, case/ referent was the dependent variable and problems at baseline and problems at follow-up were independent variables, separately for the bivariate analyses (Crude OR) and combined in the same model for the multivariate analyses (Adjusted OR). Sex stratified analyses were done for the pain and anxiety dimension, however not for the other dimensions as there were too few reporting problems to motivate further exploration.

The VAS scores of the cases and referents, and the VAS scores for boys and girls within the case and referent groups, were compared using the MannWhitney U test. When we compared baseline to followup scores in the case and referent groups we used the Wilcoxon signed rank test.

\section{Results}

The HRQoL for the adolescents with screening-detected $\mathrm{CD}$, as reported on the EQ-5D instrument, is similar to the HRQoL of the referents, both before and one year after diagnosis and initiation of the GFD, except for in the dimension of pain at follow-up, where fewer cases reported problems than referents $(12.6 \%$ and $21.9 \%$ respectively, Adjusted OR 0.50, 95\% CI 0.27-0.94) (Table 1). However, when this dimension was stratified by sex, it was revealed that the difference was between boy cases and referents at follow-up. In the sex stratified results there was a significant difference between the boys in the pain dimension at follow-up, where fewer of the screening-detected boys reported problems $(4.3 \%)$ than the boy referents (18.8\%) (Adjusted OR 0.17, 95\% CI 0.04-0.73) (Table 2).

In the anxiety dimension, both the cases and referents had an increase (from baseline to follow-up) in the proportion of adolescents who reported problems, although 
Table 1 Adolescents reporting problems (EQ-5D), before and 1 year after screening-detected celiac disease diagnosis, compared to referents without celiac disease

\begin{tabular}{|c|c|c|c|c|}
\hline \multirow{2}{*}{$\begin{array}{l}\text { Dimensions at } \\
\text { Baseline and } \\
\text { Follow-up }\end{array}$} & \multirow{2}{*}{$\begin{array}{l}\text { Screening-detected CD (cases } n=103 \text { ) } \\
n(\%) \text { with problems }\end{array}$} & \multirow{2}{*}{$\begin{array}{l}\text { Non CD (referents } n=483 \text { ) } \\
\text { n (\%) with problems }\end{array}$} & \multicolumn{2}{|c|}{ Odds Ratios $(95 \% \mathrm{Cl})^{\mathrm{a}}$} \\
\hline & & & Bivariate $\mathbf{L R}^{\mathrm{b}}$ & Multivariate $\mathrm{LR}^{\mathrm{c}}$ \\
\hline \multicolumn{5}{|l|}{ Mobility } \\
\hline Baseline & $3(2.9)$ & $11(2.3)$ & $0.78(0.21-2.84)$ & $1.28(0.35-4.68)$ \\
\hline Follow-up & $1(1.0)$ & $7(1.4)$ & $0.67(0.08-5.48)$ & $0.67(0.08-5.52)$ \\
\hline \multicolumn{5}{|l|}{ Self care } \\
\hline Baseline & 00 & $2(0.4)$ & $0.00(0.00-)$ & $0.00(0.00-)$ \\
\hline Follow-up & 00 & $2(0.4)$ & $0.00(0.00-)$ & $0.00(0.00-)$ \\
\hline \multicolumn{5}{|l|}{ Activity } \\
\hline Baseline & $3(2.9)$ & $13(2.7)$ & $0.92(0.26-3.30)$ & $1.09(0.31-3.91)$ \\
\hline Follow-up & $2(1.9)$ & $11(2.3)$ & $0.85(0.19-3.89)$ & $0.85(0.18-3.88)$ \\
\hline \multicolumn{5}{|l|}{ Pain } \\
\hline Baseline & $21(20.4)$ & $95(19.7)$ & $0.96(0.56-1.62)$ & $1.18(0.69-2.02)$ \\
\hline Follow-up & $13(12.6)$ & $106(21.9)$ & $0.51(0.28-0.96)$ & $0.50(0.27-0.94)$ \\
\hline \multicolumn{5}{|c|}{ Anxiety/Depression } \\
\hline Baseline & $13(12.6)$ & $52(10.8)$ & $0.84(0.44-1.60)$ & $1.37(0.70-2.69)$ \\
\hline Follow-up & 15 (14.6) & $95(19.7)$ & $0.70(0.39-1.26)$ & $0.65(0.35-1.20)$ \\
\hline
\end{tabular}

${ }^{a}$ Odds ratio (95\% confidence interval).

${ }^{b}$ Bivariate logistic regression using case/referent and problems reported.

${ }^{c}$ Multivariate logistic regression using case/referent and problems reported at baseline and problems reported at follow-up.

these were not significant changes (Table 1). When stratified by sex, there was no significant difference in proportion of problems reported for anxiety for the boys or girls between the cases and referents (Table 3 ).

Adolescents with screening-detected $C D$ had a median VAS score of 91 at baseline and 90 at follow-up (Table 4), which was not a significant change (Wilcoxon signed rank test, $p$ value $=0.92$ ). The referents median VAS score was 90 at baseline and at follow-up (Table 4). Comparisons of cases to referents at baseline and at follow-up showed no significant differences (MannWhitney U test, not shown).

When comparing boys and girls within the case and referent groups, the only significant difference was between the boys and girls in the referent group at followup (Mann-Whitney $\mathrm{U}$ test, $p$ value $=0.01$, not shown),

Table 2 Total adolescents, boys, and girls reporting problems in pain dimension (EQ-5D), before and 1 year after screening-detected celiac disease diagnosis, compared to referents without celiac disease

\begin{tabular}{|c|c|c|c|c|}
\hline \multirow{2}{*}{$\begin{array}{l}\text { Groups at Baseline } \\
\text { and Follow-up }\end{array}$} & \multirow{2}{*}{$\begin{array}{l}\text { Screening-detected CD (cases) } \\
\text { n (\%) with problems }\end{array}$} & \multirow{2}{*}{$\begin{array}{l}\text { Non CD (referents) } \\
\text { n (\%) with problems }\end{array}$} & \multicolumn{2}{|c|}{ Odds Ratios $(95 \% \mathrm{Cl})^{a}$} \\
\hline & & & Bivariate LR $^{\mathbf{b}}$ & Multivariate LR $^{c}$ \\
\hline Total & $n=103$ & $n=483$ & & \\
\hline Baseline & $21(20.4)$ & $95(19.7)$ & $0.96(0.56-1.62)$ & $1.18(0.69-2.02)$ \\
\hline Follow-up & $13(12.6)$ & $106(21.9)$ & $0.51(0.28-0.96)$ & $0.50(0.27-0.94)$ \\
\hline Boys & $n=47$ & $n=208$ & & \\
\hline Baseline & $13(27.7)$ & $41(19.7)$ & $1.56(0.76-3.22)$ & $1.90(0.90-4.03)$ \\
\hline Follow-up & $2(4.3)$ & $39(18.8)$ & $0.19(0.05-0.83)$ & $0.17(0.04-0.73)$ \\
\hline Girls & $n=56$ & $n=275$ & & \\
\hline Baseline & $8(14.3)$ & $54(19.6)$ & $0.68(0.31-1.53)$ & $0.72(0.32-1.62)$ \\
\hline Follow-up & $11(19.6)$ & $67(24.4)$ & $0.76(0.37-1.55)$ & $0.81(0.39-1.67)$ \\
\hline
\end{tabular}

${ }^{a}$ Odds ratio ( $95 \%$ confidence interval).

b Bivariate logistic regression using case/referent and problems reported.

${ }^{c}$ Multivariate logistic regression using case/referent and problems reported at baseline and problems reported at follow-up. 
Table 3 Total adolescents, boys, and girls reporting problems in anxiety dimension (EQ-5D), before and 1 year afte screening-detected celiac disease diagnosis, compared to referents without celiac disease

\begin{tabular}{|c|c|c|c|c|}
\hline \multirow{2}{*}{$\begin{array}{l}\text { Groups at Baseline } \\
\text { and Follow-up }\end{array}$} & \multirow{2}{*}{$\begin{array}{l}\text { Screening-detected CD (cases) } \\
\text { n (\%) with problems }\end{array}$} & \multirow{2}{*}{$\begin{array}{l}\text { Non CD (referents) } \\
\text { n (\%) with problems }\end{array}$} & \multicolumn{2}{|c|}{ Odds Ratios $(95 \% \mathrm{Cl})^{\mathrm{a}}$} \\
\hline & & & Bivariate LR $^{\mathbf{b}}$ & Multivariate $\mathrm{LR}^{\mathrm{c}}$ \\
\hline Total & $n=103$ & $n=483$ & & \\
\hline Baseline & $13(12.6)$ & $52(10.8)$ & $0.84(0.44-1.60)$ & $1.37(0.70-2.69)$ \\
\hline Follow-up & $15(14.6)$ & $95(19.7)$ & $0.70(0.39-1.26)$ & $0.65(0.35-1.20)$ \\
\hline Boys & $n=47$ & $n=208$ & & \\
\hline Baseline & $4(8.5)$ & $16(7.7)$ & $1.12(0.36-3.51)$ & $1.46(0.43-4.95)$ \\
\hline Follow-up & $2(4.3)$ & $18(8.7)$ & $0.47(0.11-2.10)$ & $0.41(0.08-1.98)$ \\
\hline Girls & $n=56$ & $n=275$ & & \\
\hline Baseline & $9(16.1)$ & $36(13.1)$ & $1.27(0.57-2.81)$ & $1.38(0.61-3.13)$ \\
\hline Follow-up & $13(23.2)$ & $77(28.0)$ & $0.78(0.40-1.53)$ & $0.73(0.37-1.47)$ \\
\hline
\end{tabular}

a Odds ratio ( $95 \%$ confidence interval).

${ }^{\mathrm{b}}$ Bivariate logistic regression using case/referent and problems reported.

c Multivariate logistic regression using case/referent and problems reported at baseline and problems reported at follow-up.

in which both report a median of 90 but for the boys and girls the $25^{\text {th }}$ percentile is 85 and 75 (respectively) and the $75^{\text {th }}$ percentile is 98.75 and 97 (respectively).

\section{Discussion}

The HRQoL for adolescents with screening-detected $\mathrm{CD}$, as self-reported on the EQ-5D, is similar to that of their peers, both before and one year after diagnosis and GFD, except in the dimension of pain at follow-up. A sex stratified analysis revealed that this is due to the difference between boy cases and referents at follow-up, in which $4.3 \%$ of the screening-detected boys report problems and $18.8 \%$ of the referent boys report problems (Adjusted OR 0.17, 95\% CI 0.04-0.73) (Table 2).

We present a unique study in which adolescents with screening-detected CD report their HRQoL before and one year after diagnosis and treatment. A strength of our study is that the adolescents report baseline HRQoL before knowledge of their $\mathrm{CD}$ diagnosis, unlike many studies in which patients are asked to recall how they felt at the time of their diagnosis. We have previously published baseline data, including participants from the same screening study, in which there was also no significant difference in HRQoL for those with unrecognized

Table 4 VAS scores of adolescents, before and 1 year after screening-detected celiac disease diagnosis, compared to referents without celiac disease

\begin{tabular}{|c|c|c|c|c|}
\hline \multirow{3}{*}{$\begin{array}{l}\text { VAS } \\
\text { scores at } \\
\text { Baseline } \\
\text { and } \\
\text { Follow-up }\end{array}$} & \multicolumn{2}{|c|}{$\begin{array}{l}\text { Screening-detected CD (cases) } \\
n=103\end{array}$} & \multicolumn{2}{|c|}{$\begin{array}{l}\text { Non CD (referents) } \\
n=483\end{array}$} \\
\hline & Median & Quartiles & Median & Quartiles \\
\hline & & $25^{\text {th }}, 75^{\text {th }}$ & & $25^{\text {th }}, 75^{\text {th }}$ \\
\hline Baseline & 91 & 85,97 & 90 & 80,99 \\
\hline Follow-up & 90 & 80,99 & 90 & 80,98 \\
\hline
\end{tabular}

CD compared to their peers without $\mathrm{CD}$ at the time of the screening [34]. However, in this current study we explore the adolescents' HRQoL before and after diagnosis and treatment.

Another strength of this study is the fact that the adolescents had their $\mathrm{CD}$ detected as a result of a screening study, and not clinically or because they were considered high risk. This means that our results may be more reflective of those living with unrecognized $C D$, which has been seen as a limitation in other studies that attempt to address the QoL for those with undiagnosed $\mathrm{CD}$ [3]. In a review of literature that addresses how screening, diagnosing, and treating "asymptomatic screening-detected individuals" affects their QoL, done by Aggarwal et al. [3], most of the studies involved CD patients who were identified from high risk groups $[19,26]$ or were compared based on what type of symptoms led to their diagnosis; i.e., typical, not typical, or those who reported they had not experienced any symptoms [23,24,28]. However, two of the studies included individuals that could be considered as screened from the general population $[3,35,36]$. In those studies, the individuals who had "typical" symptoms showed an improvement in QoL scores after one year on the GFD, while those who were supposedly symptom free had scores comparable to healthy controls at baseline and at follow-up, $[35,36]$ similar to the screening-detected adolescents in our study.

Even though the EQ-5D instrument is a validated tool and we have used the Swedish child-friendly pilot version, this tool may have limitations in the context of this study. Perhaps, it is not the ideal tool for capturing problems with subtle symptoms or feelings caused by unrecognized $\mathrm{CD}$. Also, these adolescents may have adapted to their current health situation as normal and 
at baseline rated their health status as high as possible and similar to their peers. If they did experience improvement after diagnosis and treatment, they would be unable to demonstrate improvement from the high health status previously reported. These screeningdetected adolescents were also invited to participate in another follow-up study, where they participated in focus group discussions $(\mathrm{n}=31)$ and wrote narratives $(\mathrm{n}=91)$, and when they were asked specifically about change in well-being after diagnosis, 53.8\% reported feeling better [37]. In that study, it was also shown that some of the screening-detected children only realized they had been experiencing symptoms after they had been diagnosed and treated [37].

Although it is beyond the scope of this study to provide an explanation, the finding that fewer screeningdetected boys $(4.3 \%)$ reported problems at follow-up in the dimension of pain than the boy referents $(18.8 \%)$ is interesting to consider and warrants further investigation. In a previous Swedish study, a doubled risk for symptomatic $\mathrm{CD}$ in girls compared to boys was found [38]. In this screening study, the male to female ratio for those with clinically diagnosed CD was $1: 2$ compared to 1:1 for those with screening-detected CD [8]. This difference reveals that, at the time of the screening, a larger proportion of girls compared to boys had already been diagnosed with $C D$ in routine clinical practice [8]. It could be that the boys with unrecognized CD were further progressed in their disease at baseline because they were not as likely as the girls to have been found in clinical practice. One could speculate that, even though they may not have realized the extent of their problems at baseline, they experienced benefit from the treatment resulting in fewer of these boys reporting problems with pain than the boys in the referent group, a phenomenon which was not captured for the girls. In studies involving adults, men and women have been shown to experience the burden of CD differently $[27,39,40]$. There is also research that shows men and women access health care differently [41-43] and perhaps the boys were less likely to seek or receive care. It is also a possibility that clinicians expect girls to have a higher risk of developing $\mathrm{CD}$ and more readily recognize and diagnose girls.

In our study there were no significant differences in the anxiety dimension between cases and referents, suggesting that for these screening-detected adolescents the CD diagnosis and GFD have not caused excess anxiety (at least at one year follow-up). Other studies have shown that those with a strict GFD can have the same HRQoL as healthy children/adolescents $[44,45]$. However, in the qualitative study mentioned previously [37], it was revealed that some of these adolescents perceived the GFD and lifestyle changes as inconvenient and causing feelings of stigma while others adapted well to the disease.

\section{Conclusions}

The findings of this study suggest that the adolescents with unrecognized $C D$ experience similar HRQoL as their peers without $C D$, both before and one year after the diagnosis and initiation of the GFD, except for boys in the dimension of pain at follow-up. The screeningdetected boys seem to benefit, because fewer report problems with pain than the boy referents at follow-up, one year after diagnosis and initiation of the GFD. However, further research is needed to explore why the screening-detected boys seem to have a different experience from the referent boys and from the screeningdetected girls. If considering general population screening for $\mathrm{CD}$ in the future, more research is also needed to learn more about the benefits or drawbacks of early diagnosis, long term consequences of untreated $\mathrm{CD}$, and the health economic implications of population screening.

\section{Abbreviations}

CD: Celiac disease; QoL: Quality of life; HRQoL: Health-related quality of life; GFD: Gluten-free diet; LR: Logistic regression; OR: Odds ratio; Cl: Confidence interval.

\section{Competing interests}

The authors declare that they have no competing interests.

\section{Authors' contributions}

All authors contributed to the conception or design of the study. KN, Al, LL, $\mathrm{FN}$, and $\mathrm{HS}$ contributed to the analysis. KN wrote the manuscript and all authors read and gave feedback during drafting and revising the manuscript and approved the final version.

\section{Acknowledgements}

Thank you to all adolescents and families, teachers, school nurses, and research nurses who participated in the ETICS study. This study was funded by: the Swedish Research Council (grants 521-2004-7093 and 521-2007-2953), the Swedish Research Council for Environment, Agricultural Sciences, and Spatial Planning (grants 222-2004-1918 and 222-2007-1394), the Swedish Council for Working Life and Social Research (grant 2005-0802), and by the European Union supported project (FP6-2005-FOOD-4B-36383-PREVENTCD), and was undertaken within the Umeå Centre of Global Health Research at Umeå University.

Received: 1 October 2012 Accepted: 12 February 2013

Published: 16 February 2013

\section{References}

1. Ludvigsson JF, Leffler DA, Bai JC, Biagi F, Fasano A, Green PHR, Hadjivassiliou M, Kaukinen K, Kelly CP, Leonard JN, et al: The Oslo definitions for coeliac disease and related terms. Gut 2012, 62:43-52.

2. Newton K, Singer S: Celiac disease in children and adolescents: special considerations. Semin Immunopathol 2012, 34:479-496.

3. Aggarwal S, Lebwohl B, Green PHR: Screening for celiac disease in average-risk and high-risk populations. Ther Adv Gastroenterol 2012, 5:37-47.

4. Fasano A, Berti I, Gerarduzzi T: Prevalence of celiac disease in at-risk and not-at risk groups in the United States. Arch Intern Med 2003, 163:286-292. 
5. Rubio-Tapia A, Kyle RA, Kaplan EL, Johnson DR, Page W, Erdtmann F, Brantner TL, Kim WR, Phelps TK, Lahr BD, et al: Increased prevalence and mortality in undiagnosed celiac disease. Gastroenterology 2009, 137:88-93.

6. Lohi S, Mustalahti K, Kaukinen K, et al: Increasing prevalence of coeliac disease over time. Aliment Pharmacol Ther 2007, 26:1217-1225.

7. Mearin L, Ivarsson A, Dickey W: Coelic disease: is it time for mass screening? Best Pract Res Clin Gastroenterol 2005, 19:441-452.

8. Myléus A, Ivarsson A, Webb C, Danielsson L, Hernell O, Högberg L, Karlsson E, Lagerqvist C, Norström F, Rosén A, et al: Celiac disease revealed in 3\% of swedish 12-year-olds born during an epidemic. J Pediatr Gastroenterol Nutr 2009, 49:170-176.

9. Ivarsson A, Persson LA, Juto P, Peltonen M, Suhr O, Hernell O: High prevalence of undiagnosed coeliac disease in adults: a Swedish population-based study. J Intern Med 1999, 245:63-68.

10. Rubio-Tapia A, Ludvigsson JF, Brantner TL, Murray JA, Everhart JE: The prevalence of celiac disease in the United States. Am J Gastroenterol 2012, 107:1538-1544.

11. Green PHR: The many faces of celiac disease: clinical presentation of celiac disease in the adult population. Gastroenterology 2005, 128:S74-S78

12. Fasano A: Should we screen for coeliac disease? Yes. BMJ 2009, 339:998-999.

13. Rubio-Tapia A, Van Dyke CT, Lahr BD, Zinsmeister AR, El-Youssef M, Moore SB, Bowman M, Burgart $L$, Melton lii $L$, Murray JA: Predictors of family risk for celiac disease: a population-based study. Clin Gastroenterol Hepatol 2008, 6:983-987

14. Gray A, Papanicolas I: Impact of symptoms on quality of life before and after diagnosis of coeliac disease: results from a UK population survey. BMC Health Serv Res 2010, 10:105.

15. de Lorenzo C, Xikota J, Wayhs M, Nassar S, de Souza Pires M: Evaluation of the quality of life of children with celiac disease and their parents: a case-control study. Qual Life Res 2012, 21:77-85.

16. Byström I-M, Hollén E, Fälth-Magnusson K, Johansson A: Health-related quality of life in children and adolescents with celiac disease: from the perspectives of children and parents. Gastroenterology Research and Practice 2012, 2012:6.

17. Lee A, Newman JM: Celiac diet: its impact on quality of life. J Am Diet Assoc 2003, 103:1533-1535

18. Hallert C, Grannö C, Grant C, Hulten S, Midhagen G, Ström M, Svensson H, Valdimarsson T, Wickström T: Quality of life of adult coeliac patients treated for 10 years. Scand J Gastroenterol 1998, 33:933-938.

19. Mustalahti K, Lohiniemi S, Collin P, Vuolteenaho N, Laippala P, Mäki M: Gluten-free diet and quality of life in patients with screen-detected celiac disease. Eff Clin Pract 2002, 5:105-113.

20. Ciacci C, D'Agate C, De Rosa A, Franzese C, Errichiello S, Gasperi V, Pardi A, Quagliata D, Visentini S, Greco L: Self-rated quality of life in celiac disease. Dig Dis Sci 2003, 48:2216-2220.

21. Casellas F, Rodrigo L, Vivancos JL, Riestra S, Pantiga C, Baudet JS, Junquera F, Divi VP, Abadia C, Papo M, et al: Factors that impact health-related quality of life in adults with celiac disease to multicenter study. World $J$ Gastroenterol 2008, 14:46-52.

22. Paavola A, Kurppa K, Ukkola A, Collin P, Lähdeaho M-L, Huhtala H, Mäki M, Kaukinen K: Gastrointestinal symptoms and quality of life in screendetected celiac disease. Dig Liver Dis 2012, 44:814-818.

23. Tontini GE, Rondonotti E, Saladino V, Saibeni S, de Franchis R, Vecchi M: Impact of gluten withdrawal on health-related quality of life in celiac subjects: an observational case-control study. Digestion 2010, 82:221-228.

24. Ukkola A, Mäki M, Kurppa K, Collin P, Huhtala H, Kekkonen L, Kaukinen K: Diet improves perception of health and well-being in symptomatic, but not asymptomatic, patients With celiac disease. Clin Gastroenterol Hepatol 2011, 9:118-123. e111.

25. Whitaker JKH, West J, Holmes GKT, Logan RFA: Patient perceptions of the burden of coeliac disease and its treatment in the UK. Aliment Pharmacol Ther 2009, 29:1131-1136.

26. Viljamaa M, Collin P, Huhtala H, Sievanen H, Mäki M, Kaukinen K: Is coeliac disease screening in risk groups justified? A fourteen-year follow-up with special focus on compliance and quality of life. Aliment Pharmacol Ther 2005, 22:317-324.

27. Norström F, Lindholm L, Sandström O, Nordyke K, Ivarsson A: Delay to celiac disease diagnosis and its implications for health-related quality of life. BMC Gastroenterol 2011, 11:118

28. Nachman F, Maurino E, Vazquez H, Sfoggia C, Gonzalez A, Gonzalez V, Plancer del Campo M, Smecuol E, Niveloni S, Sugai E: Quality of life in celiac disease patients: prospective analysis on the importance of clinical severity at diagnosis and the impact of treatment. Dig Liver Dis 2009, 41:15-25.

29. Ravens-Sieberer U, Wille N, Badia X, Bonsel G, Burström K, Cavrini G, Devlin N, Egmar AC, Gusi N, Herdman M, et al: Feasibility, reliability, and validity of the EQ-5D-Y: results from a multinational study. Qual Life Res 2010, 19:887-897

30. Burström K, Egmar AC, Lugner A, Eriksson M, Svartengren M: A Swedish child-friendly pilot version of the EQ-5D instrument-the development process. Eur J Public Health 2011, 21:171-177.

31. Burström K, Svartengren M, Egmar AC: Testing a Swedish child-friendly pilot version of the EQ-5D instrument-initial results. Eur J Public Health 2011, 21:178-183.

32. Brooks R, Rabin R, De Charro F: The measurement and valuation of health status using EQ-5D: A European perspective. The Netherlands: Kluwer Academic Publishers; 2003

33. Cheung K, Oemar M, Oppe M, Rosalind R: EQ-5D user guide. Basic information on how to use EQ-5D. In www.eurogol.org. 2009.

34. Nordyke K, Norström F, Lindholm L, Carlsson A, Danielsson L, Emmelin M, Högberg L, Karlsson E, Ivarsson A: Health-related quality-of-life in children with coeliac disease, measured prior to receiving their diagnosis through screening. J Med Screen 2011, 18:187-192.

35. Van Koppen EJ, Schweizer JJ, Csizmadia C, Krom Y, Hylkema HB, van Geel AM, Koopman HM, Verloove-Vanhorick P, Mearin ML: Long-term health and quality-of-life consequences of mass screening for childhood celiac disease: a 10-year follow-up study. Pediatrics 2009, 123:E582-E588.

36. Johnston SD, Rodgers C, Watson RGP: Quality of life in screen-detected and typical coeliac disease and the effect of excluding dietary gluten Eur J Gastroenterol Hepatol 2004, 16:1281-1286.

37. Rosén A, Ivarsson A, Nordyke K, Karlsson E, Carlsson A, Danielsson L, Högberg L, Emmelin M: Balancing health benefits and social sacrifices: a qualitative study of how screening-detected celiac disease impacts adolescents' quality of life. BMC Pediatr 2011, 11:32.

38. Ivarsson A, Persson L, Nyström L, Hernell O: The Swedish coeliac disease epidemic with a prevailing twofold higher risk in girls compared to boys may reflect gender specific risk factors. Eur J Epidemiol 2003, 18:677-684.

39. Hallert C, Sandlund O, Broqvist M: Perceptions of health-related quality of life of men and women living with coeliac disease. Scand J Caring Sci 2003, 17:301-307.

40. Sverker A, Ostlund G, Hallert C, Hensing G: 'I lose all these hours. ..' - exploring gender and consequences of dilemmas experienced in everyday life with coeliac disease. Scand J Caring Sci 2009, 23:342-352.

41. Will C: Constructions of masculinity and their influence on men's wellbeing:a theory of gender and health. Soc Sci Med 2000, 50:1385-1401.

42. Doyal L: Sex, gender, and health: the need for a new approach. BM 2001, 323:1061-1063.

43. Marcell A, Ford C, Pleck J, Sonenstein F: Masculine beliefs, parental communication, and male adolescents' health care use. Pediatrics 2007, 119:966-975.

44. Kolsteren MMP, Koopman HM, Schalekamp G, Mearin ML: Health-related quality of life in children with celiac disease. J Pediatr 2001, 138:593-595.

45. Ljungman G, Myrdal U: Compliance in teenagers with celiac-disease -a Swedish follow-up-study. Acta Paediatr 1993, 82:235-238.

doi:10.1186/1471-2458-13-142

Cite this article as: Nordyke et al:: Health-related quality of life in adolescents with screening-detected celiac disease, before and one year after diagnosis and initiation of gluten-free diet, a prospective nested case-referent study. BMC Public Health 2013 13:142. 